Original Article

\title{
PREPARATION AND CHARACTERIZATION OF HYDROXYPROPYL METHYLCELLULOSE PRODUCED FROM $\alpha$-CELLULOSE BETUNG BAMBOO (DENDROCALAMUS ASPER) AND IT'S EVALUATION ON GEL FORMULATION
}

\author{
MUHAMMAD HERPI AKBAR, HARMITA, HERMAN SURYADI*
}

Faculty of Pharmacy, Universitas Indonesia, Depok, 16424, Indonesia

Email: hsuryadi@farmasi.ui.ac.id

Received: 28 Apr 2020, Revised and Accepted: 09 Jun 2020

\begin{abstract}
Objective: This study aim to obtain the optimum condition of preparation of hydroxypropyl methylcellulose (HPMC) produced from $\alpha$-cellulose betung bamboo, physicochemical properties of HPMC powder and its characteristics in a gel formulation.

Methods: HPMC of betung bamboo (HPMC BB) were optimized by central composite design (CCD) using three variables (sodium hydroxide concentration, dimethyl sulfate concentration, and temperature) and five levels $(0, \pm 1$, and $\pm \alpha)$. The suggested optimum condition was subjected to further characterization. HPMC BB was characterized using Fourier transform infrared (FTIR) spectrometry, particle size analyzer (PSA), x-ray diffraction (XRD), scanning electron microscope (SEM) and compared to HPMC 60SH as the reference. Then, HPMC BB was used as a gelling agent in a gel formulation and the gel was evaluated, including appearance and homogeneity, $\mathrm{pH}$, viscosity, and spreadability.

Results: Optimum condition of preparation of HPMC BB was using sodium hydroxide $27.68 \%$ (w/v) and 1.26 ml dimethyl sulfate (based on $1 \mathrm{~g} \alpha$ cellulose) at $58.11{ }^{\circ} \mathrm{C}$ which resulted in molar substitution 0.21 and degree of substitution 2.09. The results showed that HPMC BB was a fine powder with yellowish-white color, odorless and tasteless, pH 7.02, residue on ignition 1.39\%, methoxy groups content $28.56 \%$, hydroxypropoxy groups content $7.09 \%$, mean particle size $98.595 \mu \mathrm{m}$, loss on drying 3.62\%, and moisture content 7.47\%. Flow properties of HPMC BB classified in the fair category. The infrared spectrum and diffraction patterns were relatively similar to HPMC 60SH. The gel has a good homogeneity and spreadability and viscosity $142.5 \mathrm{mPa} \cdot \mathrm{s}$. pH 6.37.
\end{abstract}

Conclusion: Based on the comparison to reference, HPMC BB showed relatively similar physicochemical and powder properties. However, HPMC $\mathrm{BB}$ is not recommended as a gelling agent in gel formulation because it has a low viscosity.

Keywords: Betung bamboo, Optimization, Characterization, Hydroxypropyl methylcellulose, Gel

(C) 2020 The Authors. Published by Innovare Academic Sciences Pvt Ltd. This is an open access article under the CC BY license (http://creativecommons.org/licenses/by/4.0/) DOI: http://dx.doi.org/10.22159/ijpps.2020v12i8.38066. Journal homepage: https://innovareacademics.in/journals/index.php/ijpps.

\section{INTRODUCTION}

Bamboo is a potential wood substitution. When compared to the wood, bamboo can grow quickly and reproducible with a controlled harvest [1]. 159 of 1250 bamboo species all over the world were found in Indonesia [2]. Bamboo species that generally used by Indonesian people are betung bamboo (Dendrocalamus asper) [3]. Betung bamboo contains $\alpha$-cellulose equal to $44.94 \%$ [4]. These high content of $\alpha$-cellulose make betung bamboo as a suitable alternative for cellulose source.

The usage of cellulose from non-wood natural resources is important to study. Utilization is generally done by chemical modification to form cellulose ethers, such as hydroxypropyl methylcellulose (HPMC), hydroxyethylcellulose (HEC), and carboxymethyl cellulose (CMC) [5]. One of the cellulose ethers that widely used as an excipient in pharmaceutical products is HPMC. In oral dosage formulations, it's used as a binder, film-coating, and extended release-matrix for tablets. In topical dosage formulations, it's used as a thickening agent, emulsifying agent, and stabilizer for gel and ointments. HPMC also used in the formulation of cosmetic products [6].

Preparation of HPMC from $\alpha$-cellulose involves two reactions, methylation and hydroxypropylation. $\alpha$-cellulose is first reacted with a sodium hydroxide solution to form alkali cellulose. Then, alkali cellulose was reacted with methylation and hydroxypropylation reagent to form methoxy and hydroxypropoxy groups, respectively $[7,8]$. The efficiency of the methylation and hydroxypropylation is influenced by the concentration of sodium hydroxide, methylation reagent and hydroxypropylation reagent, temperature, and reaction time. Study of preparation of methylcellulose from pod husk cacao cellulose showed that the condition of methylation using sodium hydroxide $20 \%(\mathrm{w} / \mathrm{v})$ and dimethyl sulfoxide $6.68 \mathrm{~g}$ (for each $5 \mathrm{~g}$ of $\alpha$-cellulose) at $55^{\circ} \mathrm{C}$ for $3 \mathrm{~h}$ resulted in degree of substitution 1.84 [9]. Another study of the preparation of methylcellulose from sugar cane bagasse cellulose showed that the use of sodium hydroxide $50 \%(\mathrm{w} / \mathrm{v})$ and dimethyl sulfate $3 \mathrm{ml}$ (for each $1 \mathrm{~g}$ of $\alpha$-cellulose) at $50{ }^{\circ} \mathrm{C}$ for $3 \mathrm{~h}$ resulted in degree of substitution 1.2 [10]. The study of hydroxypropylation on $\alpha$-cellulose betung bamboo showed that using sodium hydroxide $25 \%(\mathrm{w} / \mathrm{v}$ ) and propylene oxide $10 \mathrm{ml}$ (for each $1 \mathrm{~g}$ of $\alpha$-cellulose) at $70{ }^{\circ} \mathrm{C}$ for $3 \mathrm{~h}$ resulted in molar substitution 3.32 [11]. Another study showed that hydroxypropylation on olive tree branch cellulose using sodium hydroxide $10 \%(\mathrm{w} / \mathrm{v}$ ) and propylene oxide $115 \mathrm{~g}$ (for each $100 \mathrm{~g}$ of $\alpha$-cellulose) at $60{ }^{\circ} \mathrm{C}$ for $2 \mathrm{~h}$ resulted in molar substitution 0.39 [8]. Based on these studies, it is known that reaction conditions and sources of cellulose are related to the degree of substitution and molar substitution of HPMC obtained.

Physicochemical characteristics of HPMC are differents for each cellulose source, degree of substitution, and molar substitution [12]. Therefore, it is important to characterize HPMC obtained from $\alpha$ cellulose betung bamboo which includes the degree of substitution, molar substitution, organoleptic, identification, $\mathrm{pH}$, residue on ignition, bulk and tapped density, compressibility index, and Hausner's ratio, angle of repose, loss on drying, moisture content, analysis of infrared spectrum, analysis of particle size, analysis of $\mathrm{x}$ ray diffraction and analysis of scanning electron microscope. Furthermore, the HPMC of betung bamboo (HPMC BB) was used as a gelling agent in a gel formulation. The gel was evaluated including appearance and homogeneity, $\mathrm{pH}$, viscosity, and spreadability. The results were compared with HPMC grade 60SH (HPMC 60SH) which commercial products that commonly used. 


\section{MATERIALS AND METHODS}

\section{Instruments}

The instruments used in this study were hot plate and stirrer (IKA Hs-7) vacuum filter (Portable Diaphragm Aspirator BMX-1), oven (Heraeus), analytical balances (Sartorius Secura), water bath (Memmert WNB 14), desiccator (Duran), furnaces (Cole-Parmer), platinum crucible and other glass commonly used in the laboratory. The instruments used for analysis were $\mathrm{pH}$ meter (Eutech), FTIR spectrophotometer (Shimadzu FTIR-8400S), x-ray diffractogram (XRD Panalitycal X'Pert Pro), differential scanning calorimetry (PerkinElmer), particle size analyzer (CILAS 1190), scanning electron microscope (QUANTA 650), moisture content tester (ADAM AMB50), bulk tapped density tester (IMF BDT M4-005/04), flowmeter (Erweka GDT), UV-VIS spectrophotometer (Shimadzu UV-1601) and Brookfield viscometer model LVF dial reading (Brookfield AMETEK).

\section{Raw material}

Betung bamboo powder (Dendrocalamus asper) obtained from Badan Penelitian Tanaman Rempah dan Obat (BALITTRO) Bogor is the raw material used in this study with a certificate number of specimen: 62/HM.020/CMG/I.4.3/06/2018.

\section{Chemical material}

The chemicals used were acetic acid (Merck), bromine (Merck) dimethyl sulfate (Sigma-Aldrich), ethanol (Merck), formic acid (Merck), HPMC 60SH (Shin Etsu), isopropyl alcohol (Merck), nhexane (Merck), ninhydrin (Merck), nitric acid (Merck), phenol (Merck), phosphoric acid (Merck), potassium bromide (Merck), potassium iodide (Merck), sodium acetate (Merck), sodium hydrogen carbonate (Merck), sodium hydroxide (Merck), sodium hypochlorite (Merck), sodium nitrite (Merck), sodium sulfite (Merck), sodium thiosulfate (Merck), sulfuric acid (Merck), propylene glycol (Merck) and propylene oxide (Sigma-Aldrich).

\section{Extraction}

The coarse bamboo powder was dried in an oven at $106^{\circ} \mathrm{C}$ for $6 \mathrm{~h}$. Furthermore, it was ground to a fine powder and sieved with 80 mesh sieve. The fine bamboo powder was washed repeatedly with water, then dried at $60{ }^{\circ} \mathrm{C}$ for $24 \mathrm{~h}$ in an oven. About $300 \mathrm{~g}$ of fine bamboo powder was macerated with $3 \mathrm{l}$ of $n$-hexane: ethanol (2:1) for $24 \mathrm{~h}$ and stirred every $8 \mathrm{~h}$. The pulp was filtered and dried at room temperature [11].

\section{Isolation of $\alpha$-cellulose betung bamboo}

A total of $150 \mathrm{~g}$ of extracted fine bamboo powder was mixed $2 \mathrm{l}$ of nitric acid $3.5 \%(\mathrm{v} / \mathrm{v})$ (containing $20 \mathrm{mg}$ of sodium nitrite). The mixture then heated in a water bath at $90^{\circ} \mathrm{C}$ for $2 \mathrm{~h}$. The insoluble part was separated by vacuum filter and the residual obtained was washed with distilled water. The residu was immersed into $1.5 \mathrm{l}$ of a mixed solution containing sodium sulfite $2 \%(\mathrm{w} / \mathrm{v})$ and sodium hydroxide $2 \%(\mathrm{w} / \mathrm{v})(1: 1)$ at $50{ }^{\circ} \mathrm{C}$ for $1 \mathrm{~h}$, followed by filtration by vacuum filter and washed with distilled water. The residue was bleached by mixing it into $1 \mathrm{l}$ of a mixed solution containing sodium hypochlorite $3.5 \%(\mathrm{v} / \mathrm{v})$ and distilled water $(1: 1)$, then the mixture was heated until boiling for $10 \mathrm{~min}$. Repeat the filtering and washing processes as described before. Furthermore, the residue was mixed in $1 \mathrm{l}$ of sodium hydroxide $17.5 \%(\mathrm{w} / \mathrm{v})$ and heated at $80{ }^{\circ} \mathrm{C}$ for 30 min, followed by filtration and washing until the residue was clean. The residue was dried at $60^{\circ} \mathrm{C}$ and ground to a fine powder. The fine powder obtained is $\alpha$-cellulose [13].

\section{Preparation of hydroxypropyl methylcellulose from $\alpha$-cellulose} betung bamboo

For every \pm 5 g of $\alpha$-cellulose powder was put into a beaker glass, then mixed with $100 \mathrm{ml}$ of isopropyl alcohol and alkalized by added gradually $20 \mathrm{ml}$ of sodium hydroxide variation $(16.6 \% \mathrm{w} / \mathrm{v} ; 20 \%$ $\mathrm{w} / \mathrm{v} ; 25 \% \mathrm{w} / \mathrm{v} ; 30 \% \mathrm{w} / \mathrm{v} ; 33.4 \% \mathrm{w} / \mathrm{v})$. The mixture was stirred with a magnetic stirrer continuously at room temperature for $1 \mathrm{~h}$. Furthermore, dimethyl sulfate variation $(0.86 \mathrm{ml} ; 1 \mathrm{ml} ; 1.2 \mathrm{ml} ; 1.4$ $\mathrm{ml}$; $1.54 \mathrm{ml}$ per $\mathrm{g}$ of $\alpha$-cellulose powder) was added gradually for methylation reaction and continued by the addition of $6 \mathrm{ml}$ propylene oxide for hydroxypropylation reaction. Beaker glass was tightly closed with aluminum foil and heated at temperature variation $\left(43.2{ }^{\circ} \mathrm{C}, 50{ }^{\circ} \mathrm{C}, 60{ }^{\circ} \mathrm{C}, 70{ }^{\circ} \mathrm{C}\right.$ and $\left.76.8^{\circ} \mathrm{C}\right)$ for $3 \mathrm{~h}$ with stirring. After the reaction was completed, the mixture was cooled at room temperature. The mixture was neutralized by adding acetic acid $90 \%$ to $\mathrm{pH} 7$ and filtered with a vacuum filter. The precipitate obtained is HPMC. It was washed 3 times with ethanol $96 \%$, then dried using an oven at $50{ }^{\circ} \mathrm{C}$ for $6 \mathrm{~h}$. HPMC powder was ground to a fine powder and stored in a desiccator $[7,9,11]$.

Table 1: Levels of factors for optimization

\begin{tabular}{|c|c|c|c|c|c|c|}
\hline \multirow[t]{2}{*}{ Code } & \multirow[t]{2}{*}{ Factor } & \multicolumn{5}{|c|}{ Level of factors } \\
\hline & & $-\alpha$ & -1 & $\mathbf{0}$ & 1 & $+\alpha$ \\
\hline $\mathrm{X} 1$ & Sodium hydroxide $(\% \mathrm{w} / \mathrm{v})$ & 16.6 & 20.0 & 25.0 & 30.0 & 33.4 \\
\hline $\mathrm{X} 2$ & Dimethyl sulfate ( $\mathrm{ml} / \mathrm{g} \alpha$-cellulose) & 0.86 & 1.00 & 1.20 & 1.40 & 1.54 \\
\hline X3 & Temperature $\left({ }^{\circ} \mathrm{C}\right)$ & 43.2 & 50.0 & 60.0 & 70.0 & 76.8 \\
\hline
\end{tabular}

Table 2: Central composite design for three factors of HPMC preparation

\begin{tabular}{|c|c|c|c|c|c|c|}
\hline \multirow{2}{*}{$\begin{array}{l}\text { Trial condition of } \\
\text { preparation } \\
\text { HPMC }\end{array}$} & $\begin{array}{l}\text { Sodium } \\
\text { hydroxide (X1) }\end{array}$ & $\begin{array}{l}\text { Dimethyl } \\
\text { sulfate (X2) }\end{array}$ & $\begin{array}{l}\text { Temperature } \\
\text { (X3) }\end{array}$ & $\begin{array}{l}\text { Sodium hydroxide } \\
(\% \mathrm{w} / \mathrm{v})\end{array}$ & $\begin{array}{l}\text { Dimethyl sulfate } \\
\text { (ml/g } \alpha \text {-cellulose) }\end{array}$ & $\begin{array}{l}\text { Temperature ( } \\
\left.{ }^{\circ} \mathrm{C}\right)\end{array}$ \\
\hline & \multicolumn{3}{|c|}{ Coded levels of factors } & \multicolumn{3}{|c|}{ Actual levels of factors } \\
\hline \multicolumn{7}{|l|}{ Factorial Points } \\
\hline P1 & -1 & -1 & -1 & 20 & 1 & 50 \\
\hline $\mathrm{P} 2$ & 1 & -1 & -1 & 30 & 1 & 50 \\
\hline P3 & -1 & 1 & -1 & 20 & 1.4 & 50 \\
\hline P4 & 1 & 1 & -1 & 30 & 1.4 & 50 \\
\hline P5 & -1 & -1 & 1 & 20 & 1 & 70 \\
\hline P6 & 1 & -1 & 1 & 30 & 1 & 70 \\
\hline P7 & -1 & 1 & 1 & 20 & 1.4 & 70 \\
\hline P8 & 1 & 1 & 1 & 30 & 1.4 & 70 \\
\hline \multicolumn{7}{|l|}{ Axial Points } \\
\hline P9 & $-\alpha$ & 0 & 0 & 16.6 & 1.2 & 60 \\
\hline P10 & $+\alpha$ & 0 & 0 & 33.4 & 1.2 & 60 \\
\hline P11 & 0 & $-\alpha$ & 0 & 25 & 0.86 & 60 \\
\hline P12 & 0 & $+\alpha$ & 0 & 25 & 1.54 & 60 \\
\hline P13 & 0 & 0 & $-\alpha$ & 25 & 1.2 & 43,2 \\
\hline P14 & 0 & 0 & $+\alpha$ & 25 & 1.2 & 76.8 \\
\hline \multicolumn{7}{|l|}{ Center Points } \\
\hline P15 & 0 & 0 & 0 & 25 & 1.2 & 60 \\
\hline P16 & 0 & 0 & 0 & 25 & 1.2 & 60 \\
\hline P17 & 0 & 0 & 0 & 25 & 1.2 & 60 \\
\hline
\end{tabular}




\section{Experimental design}

The central composite rotatable design was used for the development and optimization of preparation HPMC using software Design Expert ${ }^{\circledR}$ (Version 12.0, Stat-Ease Inc) Trial version. Three factors having five levels $(0, \pm 1$, and $\pm \alpha)$ were used, designated as $\mathrm{X} 1$ : sodium hydroxide (16.6-33.4\% w/v), X2: dimethyl sulfate (0.86-1.54 $\mathrm{ml}$ per gram of $\alpha$-cellulose powder), and X3: temperature (43.2-76.8 ${ }^{\circ} \mathrm{C}$ ). Response surface methodology was used to evaluate the influence of the three factors on response variables of Y1 (degree of substitution) and Y2 (molar substitution). Different trial conditions of preparation HPMC were prepared based on the trial proposals of CCD according to the formula $\mathrm{N}=2^{\mathrm{k}}+2 \mathrm{k}+\mathrm{Co}$, where $\mathrm{k}$ is the number of factors and Co is the number of center points $[14,15]$. A total of 17 trial conditions were generated having 8 factorial points, 6 axial points, and 3 center points. The different level of factors is given in table 1 and the design matrix including the condition of preparation HPMC is shown in table 2 .

\section{Determination of degree of substitution (DS)}

The degree of substitution of HPMC was determined as reported in the literature $[7,10]$. This method based on the reaction between methoxyl groups in HPMC and the iodidric acid to form methyl iodide. The percentage of methoxyl group and the degree of substitution were determined through indirect volumetry of the iodine released by a series of chemical reactions. Iodine was titrated with sodium thiosulfate as a standard solution and a starch solution was used as an indicator of reaction. The volume of the standard solution used in the titration was recorded and used to calculate the percentage of the methoxyl group and then the degree of substitution.

\section{Determination of molar substitution (MS)}

The molar substitution was determined as reported in the literature $[12,16]$. This method based on the hydrolysis reaction of hydroxypropyl group in HPMC to propylene glycol. The propylene glycol then dehydrated into propionaldehyde and the enolic form of allyl alcohol. Furthermore, these products were reacted with ninhydrin to form purple color, the absorbance was measured using UV-VIS spectrophotometer at a wavelength of 400-415 nm [11].

\section{Organoleptic test and identification}

Organoleptic test and identification of HPMC powder based on the United States Pharmacopoeial Convention 2015 [17]. HPMC powder was placed on the white base and the appearance, color, smell, and taste were observed. Identification was carried out by dissolving $\pm 1 \mathrm{~g}$ HPMC in $100 \mathrm{ml}$ of boiled water $\left(90-99^{\circ} \mathrm{C}\right)$ and stirred with a magnetic stirrer. $0.1 \mathrm{ml}$ of this solution was transferred to a test tube and $9 \mathrm{ml}$ of sulfuric acid solution $90 \%$ was added, then shaken The sample was heated in a water bath for $3 \mathrm{~min}$. Furthermore, the sample was cooled immediately in an ice bath and added slowly 0.6 $\mathrm{ml}$ of ninhydrin then shaken. The sample was cooled at room temperature $\left(25^{\circ} \mathrm{C}\right)$. A red color develops at first that changes to purple within $10 \mathrm{~min}$.

\section{pH determination}

A total of $2 \mathrm{~g}$ of HPMC powder was dissolved in $100 \mathrm{ml}$ of boiled water $\left(90-99^{\circ} \mathrm{C}\right)$ and stirred using a magnetic stirrer for $3 \mathrm{~min}$. The sample solution was left at room temperature $\left(25^{\circ} \mathrm{C}\right)$, then the $\mathrm{pH}$ of this solution was determined using a $\mathrm{pH}$ meter [17].

\section{Residue on ignition}

The platinum crucible was ignited in a furnace at $600{ }^{\circ} \mathrm{C}$ for $15 \mathrm{~min}$ then cooled in a desiccator and weighed. A total of $1 \mathrm{~g}$ HPMC powder was weighed with the platinum crucible. Furthermore, the platinum crucible contained HPMC was ignited at $600^{\circ} \mathrm{C}$ for $6 \mathrm{~h}$. After the ash was obtained, the platinum crucible was cooled in a desiccator and weighed. Residue on ignition can be calculated by the formula [17]:

Compressibility index $=100 \times \frac{(\text { Vo }- \text { Vf })}{\text { Vo }} \quad$ Hausner's ratio $=\frac{V o}{V f}$

Where $W$ is the weight of the sample (g), $W o$ is the weight of platinum crucible (g), and $W i$ is the weight of platinum crucible and ash (g)

\section{Bulk and tapped density}

Bulk and tapped density were determined based on the United States Pharmacopoeial Convention 2014 [18]. HPMC powder was weighed about $15 \mathrm{~g}$ and transferred to a graduated cylinder and the initial volume was recorded. The graduated cylinder contained HPMC powder placed on bulk tapped density tester and setting the speed to 300 taps per min. The bulk tapped density tester was turned on and final tapped volume was recorded. Bulk density and tapped density can be calculated by the formula:

Compressibility index $=100 \times \frac{(\mathrm{Vo}-\mathrm{Vf})}{\mathrm{Vo}} \quad$ Hausner's ratio $^{\prime}=\frac{\mathrm{Vo}}{\mathrm{Vf}}$

Where $M$ is the weight of the sample (g), $V o$ is the initial volume $(\mathrm{ml})$, and $V f$ is the final tapped volume $(\mathrm{ml})$.

\section{Compressibility index and Hausner's ratio}

Compressibility index and Hausner's ratio can be calculated by the formula [18]:

Compressibility index $=100 \times \frac{(\mathrm{Vo}-\mathrm{Vf})}{\mathrm{Vo}} \quad$ Hausner's ratio $=\frac{\mathrm{Vo}}{\mathrm{Vf}}$

Where $V o$ is the initial volume (ml) and $V f$ is the final tapped volume (ml).

\section{Angle of repose}

The angle of repose was determined based on the United States Pharmacopoeial Convention 2004 [19]. About $15 \mathrm{~g}$ of HPMC powder was poured slowly into the funnel of flowmeter until the tip of powder touched the end of the funnel. Graph paper was prepared below the funnel as a base for the fall of powder. The tip of the funnel was opened slowly, so the powder can be flowed down slowly. The height and diameter of the powder formed were measured, then the angle of repose can be calculated by the formula:

Compressibility index $=100 \times \frac{(\mathrm{Vo}-\mathrm{Vf})}{\mathrm{Vo}} \quad$ Hausner's ratio $=\frac{\mathrm{Vo}}{\mathrm{Vf}}$

Where $\theta$ is the angle of repose $\left(^{\circ}\right), h$ is the height of the sample $(\mathrm{cm})$ and $D$ is the diameter of the sample $(\mathrm{cm})$.

\section{Loss on drying}

HMPC powder was weighed about $1 \mathrm{~g}$ and transferred in a porcelain crucible, then dried in an oven at $105^{\circ} \mathrm{C}$ for $1 \mathrm{~h}$. Loss on drying can be calculated by the formula [17]:

$$
\text { Compressibility index }=100 \times \frac{(\mathrm{Vo}-\mathrm{Vf})}{\mathrm{Vo}} \quad \text { Hausner's ratio }=\frac{\mathrm{Vo}}{\mathrm{Vf}}
$$

Where $W$ is the weight of crucible (g), Wo is the weight of crucible and sample before dried (g), and $W i$ is the weight of crucible and sample after dried (g).

\section{Moisture content}

The moisture content of powder was measured using moisture content tester at $105^{\circ} \mathrm{C}$. HPMC powder was weighed about $1 \mathrm{~g}$ and placed on the aluminum plate of moisture content tester. The device was turned on to measure the moisture content of HPMC powder.

\section{Analysis of infrared spectrum}

$\mathrm{KBr}$ powder was weighed About $100 \mathrm{mg}$ as blank and used to make baseline. HPMC powder was weighed about $\pm 2 \mathrm{mg}$, then added 98 $\mathrm{mg}$ of $\mathrm{KBr}$ powder and mixed homogeneously. The mixture was put in a disc-mold of the FTIR spectrophotometer. The scanning process was performed at $4000 \mathrm{~cm}^{-1}$ to $400 \mathrm{~cm}^{-1}$.

\section{Analysis of particle size}

A total of $300 \mathrm{mg}$ HPMC powder was weighed and dispersed in 20 $\mathrm{ml}$ of distilled water. The particle size of HPMC powder was measured using a particle size analyzer.

\section{Analysis of x-ray diffraction}

About $2 \mathrm{~g}$ of HPMC powder was ground to fine form and placed on the glass using adhesive. HPMC powder was characterized using an 
$\mathrm{x}$-ray diffractogram to obtained diffraction patterns. It was operated in reflection mode $(40 \mathrm{kV}, 30 \mathrm{~mA})$ and used $\mathrm{Cu}-\mathrm{K} \alpha$ radiation at $2 \theta=$ $10-90^{\circ}$.

\section{Analysis of scanning electron microscope}

A total of $50 \mathrm{mg}$ HPMC powder was weighed and placed on stable metal palladium. Samples were cleaned with blower and coated with gold and palladium in the pressurized machine, Dionspater $1492 \mathrm{x}$ $10^{-2} \mathrm{~atm}$. Furthermore, samples were put into a special room and irradiated with an electron beam powered $10 \mathrm{kV}$. This process causes the sample to emit secondary electrons that bounce can be detected by a detector scientor and amplified by an electrical circuit that produces an image on a cathode ray tube (CRT). Image shooting is done after selecting a specific part of the sample and the desired magnification to obtain a good and clear image [20].

\section{Gel formulation}

The gel was prepared by using HPMC BB and HPMC 60SH as a gelling agent. Water required for these formulations was divided into two parts. About $2 \mathrm{~g}$ of propylene glycol 400 and $1.5 \mathrm{~g}$ of ethanol were dissolved in $15 \mathrm{ml}$ water (part one). In the second part, $1.5 \mathrm{~g}$ HPMC was dissolved in
$35 \mathrm{ml}$ of boiled water $\left(90-99{ }^{\circ} \mathrm{C}\right)$. Furthermore, about $0.1 \mathrm{~g}$ of methylparaben and $0.01 \mathrm{~g}$ of propylparaben were added to the second part and stirred. The two-part of the mixture were put in a beaker glass, then stirred homogeneously. The $\mathrm{pH}$ of the mixture was adjusted to \pm 6.5 by adding triethanolamine. The mixture was stirred using a homogenizer at $500 \mathrm{rpm}$ for $2 \mathrm{~h}$. The gel obtained was stored at room temperature [21].

\section{Evaluation tests for gel}

\section{Appearance and homogeneity}

About $0.5 \mathrm{~g}$ of gel formulations were weighed and placed on transparent glass. The gel was flattered to see that all the ingredients were completely dispersed.

pH

A total of $0.1 \mathrm{~g}$ gel formulations was dissolved in $10 \mathrm{ml}$ of distilled water to obtain a gel solution $1 \% \mathrm{w} / \mathrm{v}$ and stored for $2 \mathrm{~h}$. The $\mathrm{pH}$ of the gel solution was measured using a calibrated $\mathrm{pH}$ meter and recorded after $15 \mathrm{~min}$ [22]. The $\mathrm{pH}$ was measured on a period of 0 , $1,3,5,7$, and $14 \mathrm{~d}$

Table 3: Formulation of gel using HPMC BB (Formula A) and HPMC 60SH (Formula B)

\begin{tabular}{llll}
\hline Materials & Formula A & Formula B & Function \\
\hline HPMC 60SH (\%) & - & 3 & Gelling agent \\
HPMC BB (\%) & 3 & - & Gelling agent \\
Propylene glycol 400 (\%) & 4 & 4 & Base \\
Ethanol (\%) & 3 & 3 & Solvent \\
Methylparaben (\%) & 0.2 & 0.2 & Preservative \\
Propylparaben (\%) & 0.02 & 0.02 & Preservative \\
Triethanolamine & qs & qs & pH adjustment \\
Aquadest (g) & ad 50 & ad 50 & Aqueous base \\
\hline
\end{tabular}

\section{Viscosity}

About $30 \mathrm{~g}$ of gel formulations were weighed and placed in a beaker glass. The viscosity of gel formulations was measured using a Brookfield viscometer, the rotation speed of 5, 10, and $20 \mathrm{rpm}$ at room temperature $\left(25 \pm 0.5^{\circ} \mathrm{C}\right)$ [23]. The viscosity was measured on a period of $0,1,3,5,7$, and $14 \mathrm{~d}$

\section{Spreadability}

A total of $1 \mathrm{~g}$ gel formulation was placed over a glass with graph paper prepared at the bottom. Another glass was placed on top of the gel formulation, such the gel was sandwiched between the two glasses. A 20 g weight was placed to the upper glass and the gel was pressed uniformly. The time taken to reach a diameter of spread $(6 \mathrm{~cm})$ was recorded. Spreadability was calculated by using the formula [24]:

$$
\text { Compressibility index }=100 \times \frac{(\mathrm{Vo}-\mathrm{Vf})}{\mathrm{Vo}} \quad \text { Hausner's ratio }=\frac{\mathrm{Vo}}{\mathrm{Vf}}
$$

Where $m$ is the weight tied to the upper glass ( $\mathrm{g}$ ), $l$ is the diameter of spread $(\mathrm{cm})$, and $t$ is time to reach the diameter of spread (s).

\section{RESULTS}

\section{Preparation of HPMC BB}

HPMC BB from $\alpha$-cellulose betung bamboo was manufacture using sodium hydroxide (16.6-33.4\% w/v) as alkalization reagent, dimethyl sulfate $(0.86-1.54 \mathrm{ml}$ per $1 \mathrm{~g}$ of $\alpha$-cellulose powder) as methylation reagent and propylene oxide ( $6 \mathrm{ml}$ per $5 \mathrm{~g}$ of $\alpha$-cellulose powder) as hydroxypropylation reagent at temperature variation $43.2-76.8^{\circ} \mathrm{C}$ for $3 \mathrm{~h}$. The results of the degree of substitution (DS) and molar substitution (MS) for each trial condition are shown in table 4.

Table 4: The measured responses of 17 HPMC BB preparation

\begin{tabular}{lll}
\hline Trial condition & DS & MS \\
\hline P1 & 1.89 & 0.26 \\
P2 & 1.86 & 0.27 \\
P3 & 2.17 & 0.20 \\
P4 & 2.14 & 0.22 \\
P5 & 1.82 & 0.21 \\
P6 & 1.79 & 0.24 \\
P7 & 2.06 & 0.17 \\
P8 & 2.01 & 0.19 \\
P9 & 1.98 & 0.16 \\
P10 & 2.01 & 0.23 \\
P11 & 1.74 & 0.29 \\
P12 & 2.26 & 0.19 \\
P13 & 1.86 & 0.19 \\
P14 & 1.91 & 0.24 \\
P16 & 2.08 & 0.23 \\
P17 & 2.10 & 0.24 \\
\end{tabular}


Effect of sodium hydroxide, dimethyl sulfate and temperature on degree of substitution

The effectiveness of the methylation process is closely related to the degree of substitution value of HPMC BB obtained. The degree of substitution represents the average number of hydroxyl groups per anhydroglucose unit (AGU) substituted by the methoxy group of dimethyl sulfate used in the reaction [25]. Based on responses 3D surface plots in fig. 1a, it is known that the amount of dimethyl sulfate used has a greater effect on the degree of substitution value than the concentration of sodium hydroxide and reaction temperature. The concentration of sodium hydroxide and reaction temperature has no significant effect on the degree of substitution value. The optimum concentration of sodium hydroxide which produces the highest degree of substitution value is $\pm 25 \%(\mathrm{w} / \mathrm{v}$ ) and the degree of substitution value will decrease when the concentration of sodium hydroxide used exceeds $25 \%(\mathrm{w} / \mathrm{v})$. The optimum reaction temperature which produces the highest degree of substitution value is $\pm 58{ }^{\circ} \mathrm{C}$ and the degree of substitution value will decrease when the reaction temperature exceeds $58{ }^{\circ} \mathrm{C}$. The predicted degree of substitution value was expressed in the following equation:

$\mathrm{Y} 1=-3.23036+0.060498 \mathrm{X}_{1}+2.69933 \mathrm{X}_{2}+0.086738 \mathrm{X}_{3}-0.0025 \mathrm{X}_{1} \mathrm{X}_{2}$ $0.00005 \mathrm{X}_{1} \mathrm{X}_{3}-0.00625 \mathrm{X}_{2} \mathrm{X}_{3}-0.001116 \mathrm{X}_{1}^{2}-0.653421 \mathrm{X}_{2}^{2}-0.000668 \mathrm{X}_{3}^{2}$

Effect of sodium hydroxide, dimethyl sulfate and temperature on molar substitution

The molar substitution value represents the average number of hydroxypropoxy groups for each anhydroglucose unit and indicates the effectiveness of the hydroxypropylation reaction on the preparation of HPMC [12]. Based on responses 3D surface plots in fig. $1 \mathrm{~b}$, it is known that the amount of dimethyl sulfate and concentration of sodium hydroxide used has a significant effect on the molar substitution value compared to the reaction temperature. The molar substitution value will decrease if there is an increasing amount of dimethyl sulfate used in the reaction. The concentration of sodium hydroxide has a significant effect because it has an important role to increase the reactivity of cellulose anhydroglucose units, so the hydroxypropylation reactions between cellulose and propylene oxide can occur [8]. High reaction temperature caused the decrease of molar substitution value, even though the impact is not significant. The predicted molar substitution value was expressed in the following equation:

$$
\mathrm{Y} 2=+0.334517+0.002896 \mathrm{X}_{1}-0.134797 \mathrm{X}_{2}-0.000409 \mathrm{X}_{3}
$$

\section{Optimization of CCD}

Based on 17 trial conditions and response obtained, a statistical approach used response surface methodology of Design Expert ${ }^{\circledR}$ Version 12.0 Stat-Ease Inc (Trial version) shows that the optimum conditions of preparation HPMC BB by using sodium hydroxide $27.68 \%(\mathrm{w} / \mathrm{v})$ and dimethyl sulfate $(1.26 \mathrm{ml}$ per $\mathrm{g}$ of $\alpha$-cellulose $)$ at $58.11{ }^{\circ} \mathrm{C}$. This condition is predicted to produce HPMC BB with a degree of substitution 2.11 and molar substitution 0.22 . Furthermore, the verification process of the product obtained from optimum conditions of HPMC BB preparation was done and the results shown in table 6 .

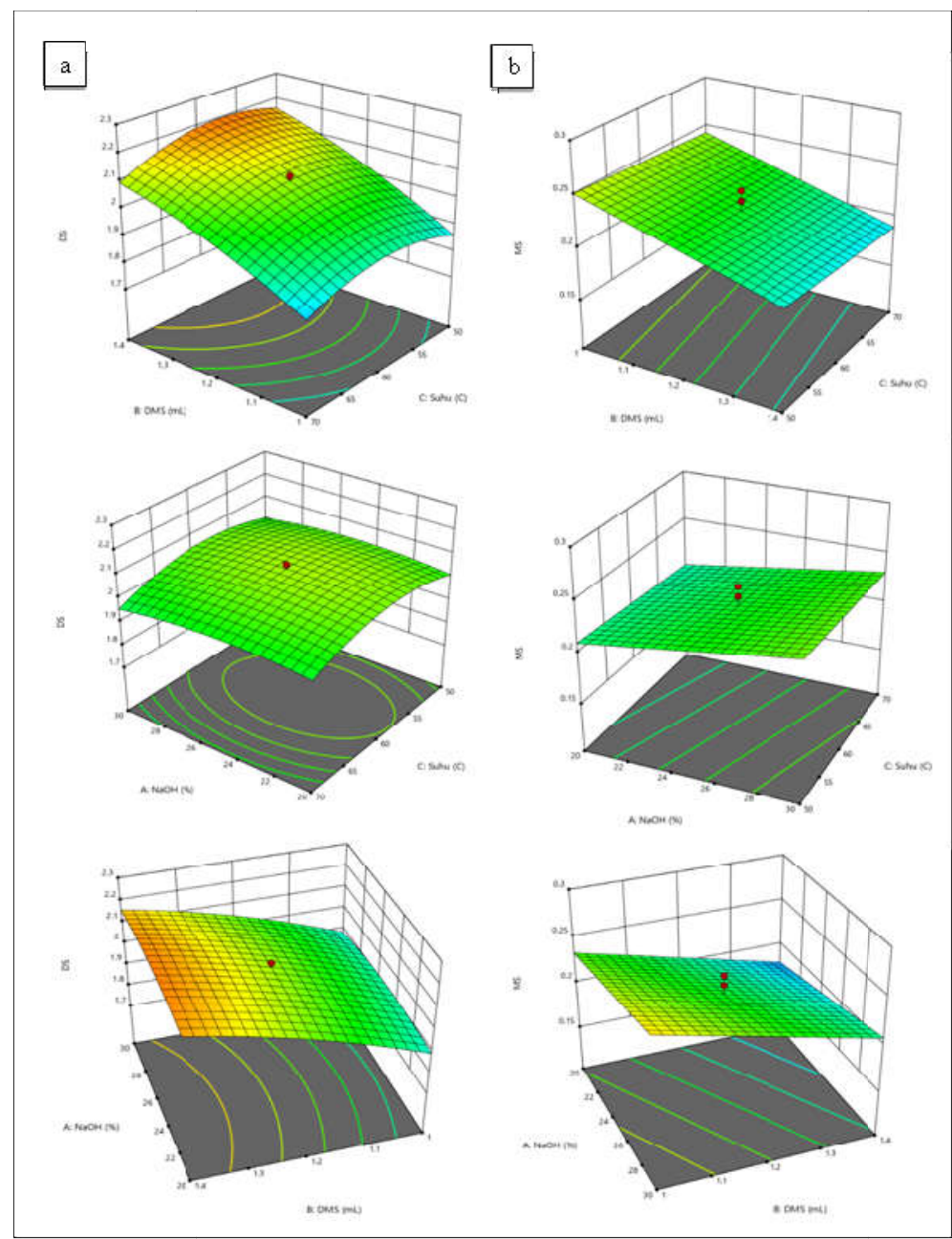

Fig. 1: Responses 3D surface plots for the effect of sodium hydroxide (X1), dimethyl sulfate (X2) and temperature (X3) on (a) degree of substitution and (b) molar substitution 
Table 5: Output data of the regression analysis of three-level three-factors of HPMC BB preparation

\begin{tabular}{|c|c|c|c|c|c|c|c|}
\hline Responses & Model & $\mathbf{R}^{2}$ & Adjusted R ${ }^{2}$ & Predicted $\mathbf{R}^{2}$ & Adequate precision & P value & Significant factors \\
\hline Y1 & Quadratic & 0.9447 & 0.8737 & 0.5871 & 11.7188 & 0.0208 & $\mathrm{X} 2$ \\
\hline Y2 & Linear & 0.6610 & 0.5827 & 0.3821 & 8.2837 & 0.0023 & $\mathrm{X} 1, \mathrm{X} 2$ \\
\hline
\end{tabular}

Y1: degree of substitution, Y2: molar substitution, X1: sodium hydroxide, X2: dimethyl sulfate

Table 6: Predicted and observed values for the optimum HPMC BB

\begin{tabular}{lll}
\hline Responses & Predicted & Observed \\
\hline Degree of substitution & 2.11 & 2.09 \\
Molar substitution & 0.22 & 0.21 \\
\hline
\end{tabular}

\section{Physicochemical properties of HPMC}

The organoleptic test shows that HPMC BB is a fine powder with yellowish-white color, odorless, and tasteless (fig. 2). The physicochemical properties of HPMC BB and HPMC 60SH are shown in table 7. Based on The United States Pharmacopoeial Convention 2015 HPMC BB fulfills the requirements of identification test, methoxy, and hydroxypropoxy groups content, $\mathrm{pH}$, and residue on ignition. The results show that HPMC BB has methoxy groups content on ranges from 28.0$30.0 \%$, hydroxypropoxy groups content on ranges from $7.0-12.0 \%, \mathrm{pH}$ on ranges from 5.0-8.0, and residue on ignition was not more than $1.5 \%$ [17]. The methoxy group content can be used to calculate the degree of substitution (DS) and hydroxypropoxy group content can be used to calculate the molar substitution (MS). DS and MS value of HPMC BB is 2.09 and 0.21 , respectively. It is not significantly different from HPMC $60 \mathrm{SH}$ with DS and MS value of 2.13 and 0.27 , respectively.

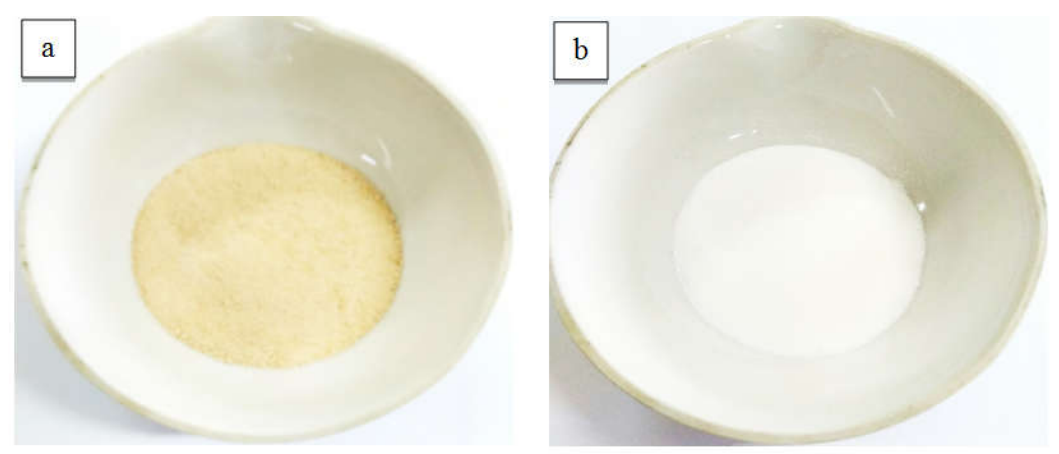

Fig. 2: HPMC BB powder (a) and HPMC 60SH powder (b)

Table 7: Physicochemical properties of HPMC

\begin{tabular}{|c|c|c|}
\hline Parameters & HPMC BB & HPMC 60SH \\
\hline Identification & + & + \\
\hline $\mathrm{pH}^{\mathrm{a}}$ & $7.02 \pm 0.01$ & $5.19 \pm 0.02$ \\
\hline Residu on ignition $(\%)^{\mathrm{b}}$ & $1.39 \pm 0.03$ & $0.17 \pm 0.04$ \\
\hline Assay of methoxy groups $(\%)^{\mathrm{b}}$ & $28.56 \pm 0.04$ & $28.93 \pm 0.03$ \\
\hline Assay of hydroxypropoxy group (\%) & $7.09 \pm 0.02$ & $9.07 \pm 0.02$ \\
\hline
\end{tabular}

amean \pm SD (standard deviation), $\mathrm{n}=3$, bmean \pm SD (standard deviation), $\mathrm{n}=2$

\section{Powder properties of HPMC}

There is a significant difference in the powder properties of HPMC $\mathrm{BB}$ and HPMC 60SH. Flow properties of HPMC BB fall into the better category than HPMC 60SH. However, test results of loss on drying and moisture content show that HPMC BB is not better than HPMC $60 \mathrm{SH}$. The complete characteristics of HPMC BB powder and HPMC $60 \mathrm{SH}$ powder are shown in table 8.

Table 8: Powder properties of HPMC

\begin{tabular}{lll}
\hline Parameters & HPMC BB & HPMC 60SH \\
\hline${\text { Bulk density }(\mathrm{g} / \mathrm{ml})^{\mathrm{a}}}_{\text {Tapped density }(\mathrm{g} / \mathrm{ml})^{\mathrm{a}}}$ & $0.58 \pm 0.001$ & $0.40 \pm 0.003$ \\
Flow properties: & $0.72 \pm 0.002$ & $0.56 \pm 0.001$ \\
Angle of repose $\left({ }^{\circ}\right)^{\mathrm{a}}$ & $20.31 \pm 0.82$ & $33.49 \pm 0.24$ \\
Hausner's ratio $^{\mathrm{a}}$ & $1.24 \pm 0.004$ & $1.38 \pm 0.010$ \\
${\text { Compressibility index }(\%)^{\mathrm{a}}}_{\text {Loss } \text { on drying }(\%)^{\mathrm{b}}}$ & $19.26 \pm 0.285$ & $27.53 \pm 0.532$ \\
${\text { Moisture content }(\%)^{\mathrm{a}}}$ & $3.62 \pm 0.168$ & $2.24 \pm 0.135$ \\
\end{tabular}

amean \pm SD (standard deviation), $\mathrm{n}=3$, ${ }^{\mathrm{b}}$ mean $\pm \mathrm{SD}$ (standard deviation), $\mathrm{n}=2$ 


\section{Analysis of infrared spectrum}

Infrared spectrum analysis aims to confirm the presence of the functional groups of HPMC BB. It was done by comparing the infrared spectrum of HPMC BB with HPMC 60SH (fig. 3). Overall, the infrared spectrum of HPMC BB has similar shapes and identical peaks to HPMC 60SH.

\section{Analysis of particle size}

Analysis using a particle size analyzer aims to determine the particle size distribution and mean particle size of HPMC BB. The results were compared with the HPMC $60 \mathrm{SH}$ as a reference standard (table 9). The results show that HPMC BB has a PDI value greater than HPMC $60 \mathrm{SH}$. Another result of HPMC BB shows that $50 \%$ of the particle population has a size smaller than $111.517 \mu \mathrm{m}$ and $90 \%$ of the particle population has a size smaller than $159.535 \mu \mathrm{m}$ with mean particle size $98.595 \mu \mathrm{m}$. Whereas the results of HPMC $60 \mathrm{SH}$ $50 \%$ of the particle population has a size smaller than $22.731 \mu \mathrm{m}$ and $90 \%$ of the particle population has a size smaller than 52.387 $\mu \mathrm{m}$ with mean particle size $24.937 \mu \mathrm{m}$.

\section{Analysis of crystal by $x$-ray diffraction}

The diffraction pattern of HPMC BB and HPMC 60SH are shown in fig. 4. The sharp peak of HPMC BB is at $2 \theta=19.86$ with an intensity of 537 , while HPMC $60 \mathrm{SH}$ is at $2 \theta=19.41$ with an intensity of 777 . However, there is no broad peak formed either in HPMC BB or HPMC 60SH. Based on the comparison of sharp peak intensities, it is known that HPMC 60SH has a higher crystalline composition than HPMC BB.

\section{Analysis of morphology by scanning electron microscope}

The scanning electron microscope analysis aims to determine the shape and surface morphology of HPMC BB and compared it with HPMC $60 \mathrm{SH}$ as a reference. There are significant differences in the shape and surface morphology between HPMC BB and HPMC 60SH. Based on the results of the analysis in fig. 5, it is known that HPMC BB has an oval shape with a rough surface. Whereas the analysis of HPMC 60SH showed irregular shape with a smoother surface than HPMC BB.

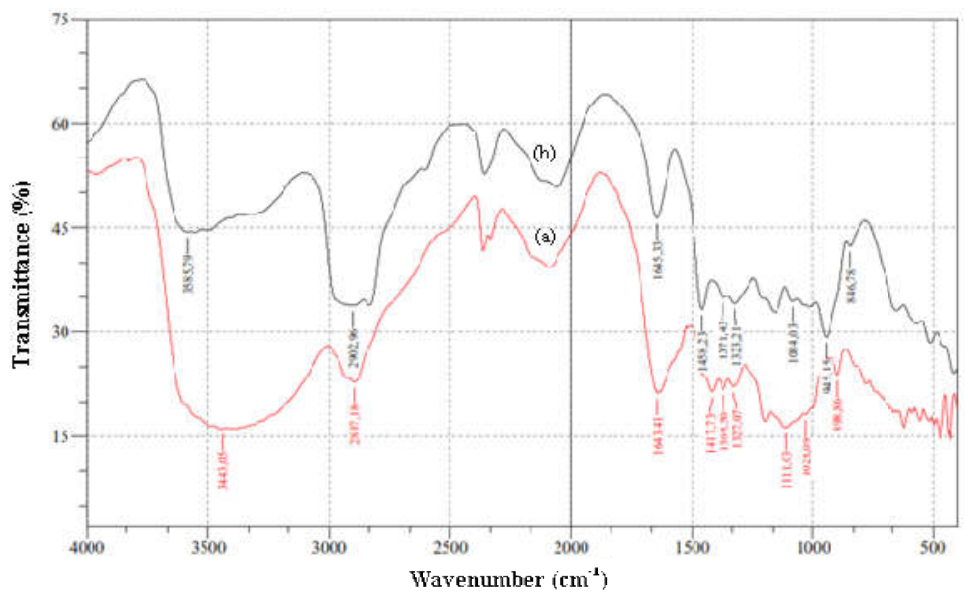

Fig. 3: Infrared spectrum of HPMC BB (a) and HPMC 60SH (b)

Table 9: Result of particle size analysis of HPMC BB and HPMC 60SH

\begin{tabular}{llllll}
\hline & PDI & D10 $(\boldsymbol{\mu m})$ & D50 $(\boldsymbol{\mu m})$ & D90 $(\boldsymbol{\mu m})$ & \multicolumn{1}{c}{ Mean $(\boldsymbol{\mu m})$} \\
\hline HPMC BB & 1.378 & 1.904 & 111.517 & 159.535 & 98.595 \\
HPMC 60SH & 0.770 & 2.147 & 22.731 & 52.387 & 24.937 \\
\hline
\end{tabular}

PDI: polydispersity index, D10: particle size of $10 \%$ particle population, D50: particle size of $50 \%$ particle population, D90: particle size of $90 \%$ particle population
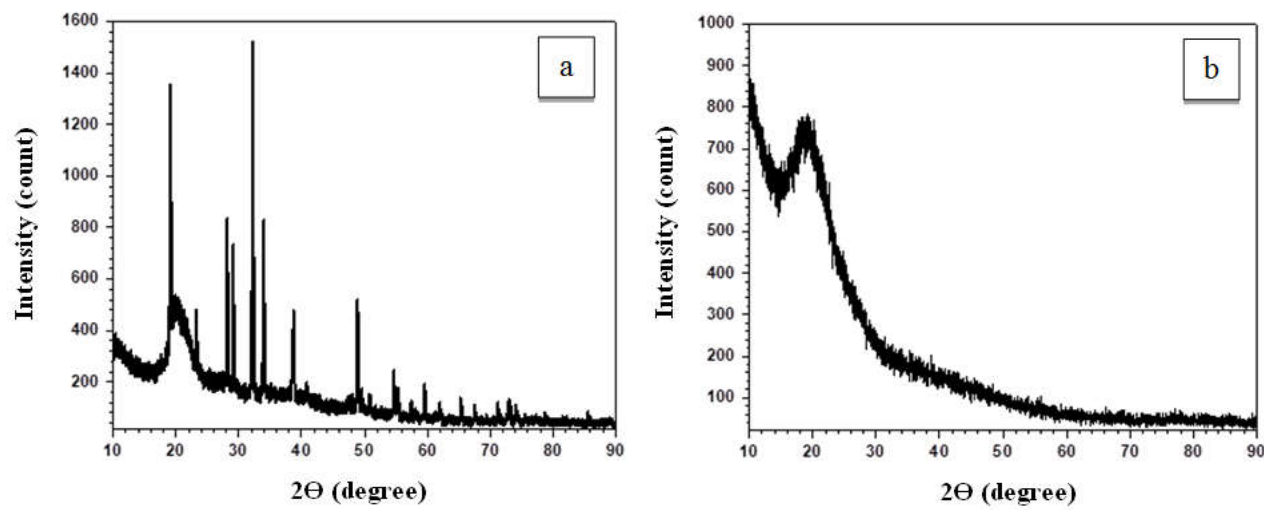

Fig. 4: Diffraction pattern of HPMC BB (a) dan HPMC 60SH (b) 

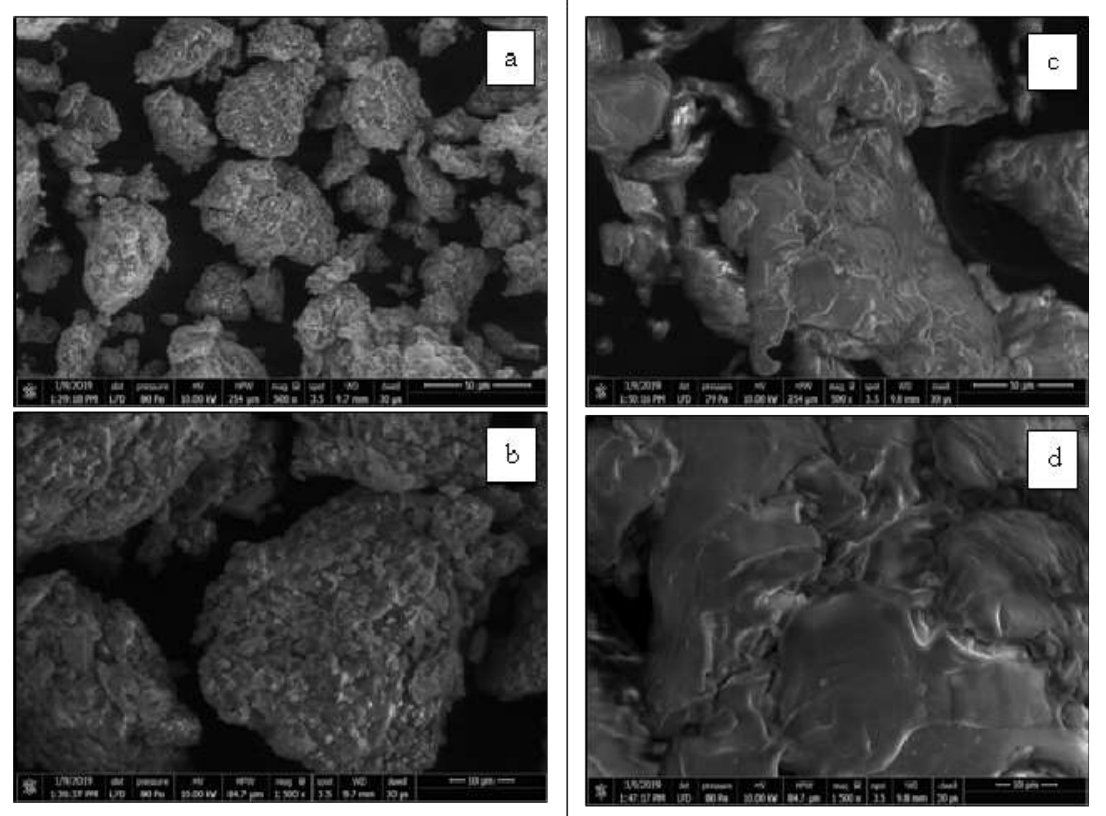

Fig. 5: Results of SEM analysis on HPMC BB at M=500x (a) and M=1500x (b) and HPMC 60SH at M=500x (c) and M=1500x (d)

\section{Gel evaluation}

The gel evaluation included appearance and homogeneity, $\mathrm{pH}$, viscosity, and spreadability. The gel preparation with HPMC BB as a gelling agent has a slightly yellowish-white, transparent, and homogeneous, while the HPMC 60SH gel has a clear appearance and homogeneous (fig. 6). The pH and viscosity of gel were measured on a period of $0,1,3,5,7$, and $14 \mathrm{~d}$. The results in table 10 shows there is no significant difference between the $\mathrm{pH}$ of HPMC BB gel and HPMC $60 \mathrm{SH}$ gel in the period of 0 to $14 \mathrm{~d}$. However, the viscosity tests show significant differences between HPMC BB gel with viscosity $142.5 \mathrm{mPa} \cdot \mathrm{s}$ and HPMC $60 \mathrm{SH}$ gel with viscosity 35166.67 $\mathrm{mPa} \cdot \mathrm{s}$. The viscosity of both gel preparations decreases significantly on day 1 . Another results shows that HPMC BB gel has spreadability $7.23 \pm 0.188 \mathrm{~g} \mathrm{~cm} / \mathrm{s}(\mathrm{n}=3)$ and HPMC $60 \mathrm{SH}$ gel has spreadability $2.63 \pm 0.022 \mathrm{~g} \mathrm{~cm} / \mathrm{s}(\mathrm{n}=3)$.

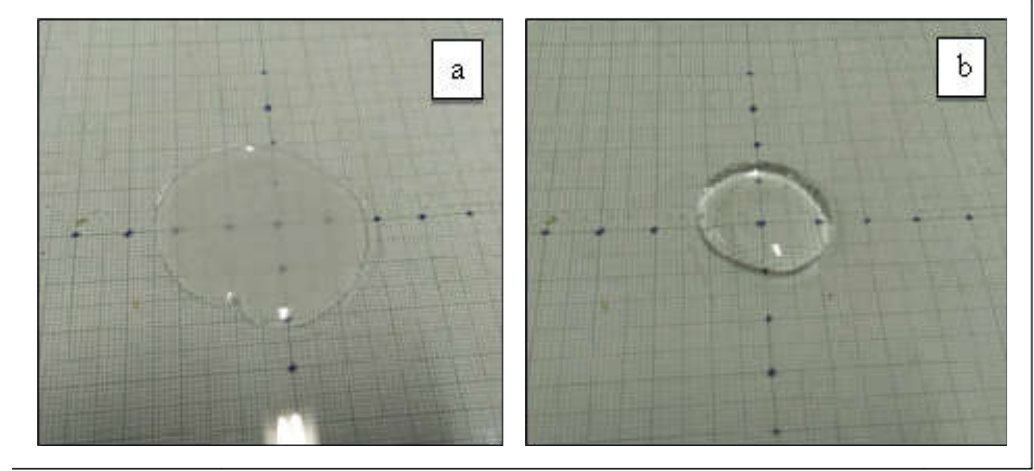

Fig. 6: Appearance of HPMC BB gel (a) and HPMC 60SH gel (b)

Table 10: pH and viscosity of HPMC BB gel and HPMC 60SH gel

\begin{tabular}{|c|c|c|c|c|c|c|}
\hline & Day 0 & Day 1 & Day 3 & Day 5 & Day 7 & Day 14 \\
\hline pH-HPMC BB gel ${ }^{a}$ & $6.37 \pm 0.005$ & $6.08 \pm 0.005$ & $6.05 \pm 0.015$ & $5.99 \pm 0.015$ & 5.94 & $5.90 \pm 0.005$ \\
\hline -HPMC 60SH gel ${ }^{a}$ & $6.29 \pm 0.005$ & $6.11 \pm 0.010$ & $6.11 \pm 0.005$ & $6.11 \pm 0.005$ & $6.10 \pm 0.005$ & $6.02 \pm 0.005$ \\
\hline Viscosity-HPMC BB gel (mPa·s) & 142.50 & 89.17 & 88.33 & 85.83 & 85.83 & 83.33 \\
\hline -HPMC 60SH gel (mPa.s) & 35166.67 & 26000.00 & 23916.67 & 22833.33 & 22083.33 & 21750.00 \\
\hline
\end{tabular}

${ }^{a}$ mean \pm SD (standard deviation), $\mathrm{n}=2$

\section{DISCUSSION}

Response surface methodology is a statistical approach used to evaluate the influence of the three factors (concentration of sodium hydroxide, amount of dimethyl sulfate and reaction temperature) on response variables, degree of substitution (DS), and molar substitution (MS). The amount of dimethyl sulfate used has a greater effect on DS value than the other factors. The greater amount of 
dimethyl sulfate used, the higher value of the DS obtained. This is probably due to a large number of methoxy groups in the reaction environment that can increase the possibility to form a bond. On the other hand, excessively used dimethyl sulfate can reduce the MS value. This is probably due to the competition between the methoxy group of dimethyl sulfate with hydroxypropoxy groups of propylene oxide to form a bond on the anhydroglucose unit of cellulose. The methoxy group has a high reactivity on the $\mathrm{C} 2, \mathrm{C} 3$, and $\mathrm{C} 6$ atoms of anhydroglucose units, whereas the hydroxypropoxy group tends reactive to the $\mathrm{C} 6$ atoms of anhydroglucose units [9]. The concentration of sodium hydroxide used has a more significant effect on DS and MS values than reaction temperature. Sodium hydroxide has an important role to increase the reactivity of anhydroglucose units which is related to the swelling ability of cellulose. In this condition, a bond will be formed on- $\mathrm{OH}$ group becoming Na-cellulose. Na-cellulose will be reacted with dimethyl sulfate and propylene oxide, $\mathrm{Na}^{+}$will be substituted to form methoxy and hydroxypropoxy groups [25]. Although the impact is not significant, high reaction temperatures can reduce the value of DS and MS. This is probably due to the role of temperature in helping the diffusion of sodium hydroxide into cellulose. Insignificant temperature differences will not affect this mechanism [26].

Organoleptic tests showed that HPMC BB has a different color from HPMC 60SH and the residu of ignition was closed to the maximum limit required on The United States Pharmacopeia 39-2015 [17] These problems probably caused by the presence of sodium hydroxide residues contained in the product [9]. The reaction temperature of HPMC BB preparation is not too high, so the effect of reaction temperature does not significantly influence the color of the product. The problem can be solved by washed the final product repeatedly until a product with a color close to white was obtained [27]. Both HPMC BB and HPMC 60SH have similar methoxy groups and hydroxypropoxy groups content and classified into the HPMC with a substitution type 2910 [17].

The flow properties of HPMC BB were determined by indirect methods based on the angle of repose, Hausner's ratio, and compressibility index. HPMC BB dan HPMC 60SH falls into a fair and poor category, respectively [19]. These results indicate that HPMC BB also has the potential as an excipient in solid formulations. The moisture content of HPMC BB is slightly different from HPMC $60 \mathrm{SH}$, but it still fulfills the requirements [6]. These problems can be fixed by optimization of the drying process of the final product.

Identical characteristics of the HPMC spectrum is in the region of wavenumbers $3600-3400 \mathrm{~cm}^{-1}, 3000-2800 \mathrm{~cm}^{-1}$ and $1500-800 \mathrm{~cm}^{-1}$. In the wavenumber $3600-3400 \mathrm{~cm}^{-1}$, there is a peak of $\mathrm{O}-\mathrm{H}$ stretching with low intensity. This is evidence of methylation and hydroxypropylation reactions in $\alpha$-cellulose, where the hydroxy group of anhydroglucose unit was replaced by a methoxy group of dimethyl sulfate and hydroxypropoxy group of propylene oxide [10, $12]$. In the wavenumber $3000-2800 \mathrm{~cm}^{-1}$ two peaks are formed close together. This is evidence of hydroxypropylation reactions that caused the formation of the $\mathrm{C}-\mathrm{H}$ stretching from $\mathrm{CH}_{3}$ which the part of $\left[\mathrm{CH}_{2} \mathrm{CH}\left(\mathrm{CH}_{3}\right) \mathrm{O}\right] \mathrm{H}$ and the $\mathrm{C}-\mathrm{H}$ stretching from $\mathrm{CH}_{2}$ which generally owned by $\alpha$-cellulose $[11,12]$. In the wavenumber $1500-800 \mathrm{~cm}^{-1}$, several peaks are formed which indicate the existence of $\mathrm{C}-\mathrm{H}$ bending and $\mathrm{C}-\mathrm{O}$ stretching bonds. The $\mathrm{C}-\mathrm{H}$ bending from $\mathrm{CH}_{3}$ that appears around $1450 \mathrm{~cm}^{-1}$ and $1375 \mathrm{~cm}^{-1}$ is one of the evidence of methylation reaction in $\alpha$-cellulose. Other evidence of methylation reaction also shown by the presence of $\mathrm{C}-\mathrm{O}$ stretching from $\mathrm{OCH}_{3}$ that appears at wavenumbers $1250-1000 \mathrm{~cm}^{-1}$ [10].

The particle size distribution is related to the Polydispersity Index (PDI) value. PDI describes the level of heterogeneity or unequal distribution of particle size. PDI value less than 0.05 indicates that the sample has a high level of homogeneity. While PDI values more than 0.7 indicates that the sample is heterogeneous and has a broad particle size distribution [28]. Both HPMC BB and HPMC 60SH fall into heterogeneous samples and have a broad particle size distribution because the PDI values are more than 0.7. HPMC BB has a significant difference in mean particle size compared to HPMC
60SH. Despite that, it still fulfills the standard range of HPMC particle size at 20-200 $\mu \mathrm{m}$ [29].

In the x-ray diffraction analysis, the crystalline form of the powder will produce a sharp peak while the amorph form will produce a broad peak [13]. Both HPMC BB and HPMC 60SH diffraction pattern did not show a broad peak, significantly. This is probably due to the small intensity of the broad peak, which related to the composition of the amorph form of HPMC BB and HPMC 60SH powder [7]. Based on the comparison of sharp peak intensities around $2 \theta=20$, it is known that HPMC 60SH has a higher crystalline composition than HPMC BB. Despite that, both HPMC BB and HPMC 60SH show relatively similar diffraction patterns.

Analysis of scanning electron microscope shows that HPMC BB has an oval shape with a rough surface. The oval shape and rough surface also found in other studies published by suryadi [11], about the modification of $\alpha$-cellulose of Betung bamboo. The rough surface morphology of modified $\alpha$-cellulose can be caused by the etherification reaction. In the etherification reaction, the residual deposition of dimethyl sulfate or propylene oxide can be formed on the surface of $\alpha$-cellulose and caused the surface morphology to become rough. This effect can be minimized by optimizing the washing process of the final product. The residual of lignin also can be caused the rough surface of the product due to the suboptimal of the delignification process during isolation of $\alpha$-cellulose. This problem can be fixed by increasing the duration of the delignification or repeating the delignification process [13].

The characteristics of HPMC BB gel showed similar appearance, homogeneity, and $\mathrm{pH}$, but there are significant differences in viscosity and spreadability compared to HPMC $60 \mathrm{SH}$ gel. Good gel preparations have no grain in the gel and must fulfill the skin $\mathrm{pH}$ criteria 4.50-6.50 to prevent skin irritation, HPMC BB gel fulfills these requirements $[30,31]$. Good gel preparations must fulfill the viscosity criteria $2000-40000 \mathrm{mPa} \cdot \mathrm{s}$. HPMC BB gel has viscosity $142.5 \mathrm{mPa} \cdot \mathrm{s}$, does not fulfill the requirement [32]. The difference of viscosity probably due to the significant difference in the molecular weight of HPMC BB and HPMC 60SH which used as gelling agents [33]. It needs to be reviewed about the use of HPMC BB as a gelling agent. HPMC BB gel has a greater spreadability compared to HPMC 60SH gel. Despite that, it does not mean that HPMC BB gel has better characteristics. A good gel preparation must have a large spreadability and also resistance to flow sufficiently, so the gel preparation was applied easily to the skin and does not flow easily after it was applied [22, 23].

\section{CONCLUSION}

The optimum condition of preparation of HPMC BB was using sodium hydroxide $27.68 \%(\mathrm{w} / \mathrm{v})$ and $1.26 \mathrm{ml}$ dimethyl sulfate (based on $1 \mathrm{~g} \alpha$-cellulose) at $58.11^{\circ} \mathrm{C}$. HPMC BB showed similar characteristics to reference on identification test, methoxy groups content, hydroxypropoxy group's content, infrared spectrum, x-ray diffraction pattern, and loss on drying. There were slight differences in $\mathrm{pH}$, residue on ignition, flow properties, moisture content, mean particle size, and surface morphological compared to the reference. However, HPMC BB still fulfills the requirements of The United States Pharmacopoeia 39-2015. HPMC BB gel showed similar characteristics on appearance, homogeneity, and $\mathrm{pH}$ compared to reference gel, but there were significant differences in viscosity and spreadability.

\section{ACKNOWLEDGMENT}

The authors gratefully acknowledge to Directorate of Research and Community Service, Universitas Indonesia for financial support (Hibah Q1Q2) of this research.

\section{AUTHORS CONTRIBUTIONS}

The authors jointly declare that they have contributed to the research work. Muhammad Herpi Akbar has conducted the experiments, collected, and treated the data under the supervision of Herman Suryadi and Harmita. The preparation, corrections, and revision of this manuscript have also been carried out by all authors. 


\section{CONFLICTS OF INTERESTS}

The authors declare the absence of any conflicting interests regarding this work and its publication.

\section{REFERENCES}

1. Scurlock JMO, Dayton DC, Hames B. Bamboo: an overlooked biomass resource. Oak Ridge: Oak Ridge National Laboratory; 2000.

2. Dransfield S, Widjaja EA. Plant resources of South-East Asia No.7: Bamboos. Leiden: Backhuys Publishers; 1995.

3. Quattrocchi UFLS. CRC world dictionary of medicinal and poisonous plants: common names, scientific names, eponyms, synonyms, and etymology. Boca Raton: CRC Press Taylor and Francis Group; 2012.

4. Loiwatu M, Manuhuwa E. Chemical component and anatomica feature of three bamboo species from seram, maluku [Komponen Kimia dan Anatomi Tiga Jenis Bambu dari Seram, Maluku]. Agritech 2008;28:76-83.

5. Nasatto PL, Pignon F, Silveira JLM, Duarte MER, Noseda MD Rinaudo M. Methylcellulose, a cellulose derivative with original physical properties and extended applications. Polymers 2015;7:777-803.

6. Rowe RC, Sheskey PJ, Quinn ME. editors. Handbook of pharmaceutical excipients. $6^{\text {th }}$ Ed. Grayslake and washington DC: American Pharmacist Association and Pharmaceutical Press; 2009.

7. Vieira JG, Filho GR, Meireles CDS, Faria FAC, Gomide DD, Pasquini D. Synthesis and characterization of methylcellulose from cellulose extracted from mango seeds for use as a mortar additive. Polimeros 2012;22:80-7.

8. Abdel Halim ES, Alanazi HH, Al-Deyab SS. Utilization of olive tree branch cellulose in synthesis of hydroxypropy carboxymethyl cellulose. Carbohydr Polym 2015;127:124-34

9. Hutomo GS. Synthesis and characterization of cellulose derivate from Pod Husk Kakao (Theobrome cacao L.)[Sintesis dan Karakterisasi Turunan Selulosa dari Pod Husk Kakao (Theobrome cacao L.)]. Dissertation. Yogyakarta: Universitas Gadjah Mada; 2012

10. Viera RGP, Filho GR, Assuncao RMND, Meireles CS, Vieira JG, Oliveira GSD. Synthesis and characterization of methylcellulose from sugar cane bagasse cellulose. Carbohydr Polym 2007;67:182-9.

11. Suryadi H, Harmita, Akbar MH, Lestari P. Characterization of hydroxypropyl cellulose produced from $\alpha$-cellulose betung bamboo (Dendrocalamus asper) and it's application in tablet formulation. Int J Appl Pharm 2019;11:123-9.

12. Sharma R, Varshney VK, Chauhan GS. Hydroxypropylation of cellulose isolated from bamboo (Dendrocalamus strictus) with respect to hydroxypropoxyl content and rheological behavior of the hydroxypropyl cellulose. J Appl Polym Sci 2009;113:2450-5.

13. Kharismi RRAY, Sutriyo, Suryadi $H$. Preparation and characterization of microcrystalline cellulose produce from betung bamboo (Dendrocalamus asper) through acid hydrolysis. J Young Pharm 2018;10:79-83.

14. Bushra R, Shoaib MH, Ali H, Zafar F, Naeem MI, Aslam N, et al Formulation design and optimization of aceclofenac tablets $(100 \mathrm{mg}$ ) using central composite design with response surface methodology. Latt Am J Pharm 2014;33:1009-18.

15. Aziz DE, Abdelbary AA, Elassasy AI. Implementing central composite design for developing transdermal diacerein-loaded niosomes: ex vivo permeation and in vivo deposition. Curr Drug Delivery 2018;15:1330-42.

16. Johnson DP. Spectrophotometric determination of the hydroxypropyl group in starch ethers. J Anal Chem 1969;41:859.

17. United States Pharmacopoeial Convention. The United States Pharmacopeia (USP) 39-NF 34. Hypromellose monograph. Rockville: The United States Pharmacopoeial Convention; 2015.

18. United States Pharmacopoeial Convention. The United States Pharmacopeia (USP) 38-NF 33. Bulk Density and Tapped Density of Powders. Rockville: The United States Pharmacopoeial Convention; 2014.

19. United States Pharmacopoeial Convention. The United States Pharmacopeia (USP) 27-NF 22. Powder Flow. Rockville: The United States Pharmacopoeial Convention; 2004.

20. Suryadi H, Sutriyo, Sari HS, Rosikhoh D. Preparation of microcrystalline cellulose from water hyacinth powder by enzymatic hydrolysis using cellulase of local isolate. J Young Pharm 2017;9:19-23.

21. Bhinge SD, Bhutkar MA, Randive DS, Wadkar GH, Todkar SS, Kakade PM, et al. Formulation development and evaluation of antimicrobial polyherbal gel. Ann Pharm Fr 2017;73:349-58.

22. Dantas MGB, Reis SAGB, Damasceno CMD, Rolim LA, Neto PJR, Carvalho FO, et al. Development and evaluation of stability of a gel formulation containing the monoterpene borneol. Sci World J 2016;1-4. https://doi.org/10.1155/2016/7394685

23. Manna S, Lakshmi US, Racharla M, Sinha P, Kanthal LK, Kumar SPN. Bioadhesive HPMC gel containing gelatin nanoparticles for intravaginal delivery of tenofovir. J Appl Pharm Sci 2016;6:22-9.

24. Joshua JM, Anilkumar A, Verjina C, Vasudevan DT, Surendran S. Formulation and evaluation of antiaging phytosomal gel. Asian J Pharm Clin Res 2018;11:409-22.

25. Othmer K. Encyclopedia of chemical technology. $4^{\text {th }}$ Ed. Vol 5. Michigan: Wiley; 2001.

26. Riviani E. Synthesis and characterization of hydroxypropyl cellulose (HPC) snake fruit (Salacca edulis Reinw) pondoh super kernel [Sintesis dan karakterisasi hydroxypropyl cellulose (HPC) dari biji salak (Salacca edulis Reinw) pondoh super]. Thesis. Yogyakarta: Universitas Gadjah Mada; 2016.

27. Ohwoavworhua FO, Adelakun TA, Okhamafe AO. Processing pharmaceutical grade microcrystalline cellulose from groundnut husk: extraction methods and characterization. Int J Green Pharm 2009;3:97-104.

28. Danaei M, Dehghankhold M, Ataei S, Hasanzadeh DF, Javanmard R, Dokhani A, et al. Impact of particle size and polydispersity index on the clinical applications of lipidic nanocarrier systems. Pharmaceutics 2018;10:1-17.

29. Heng PWS, Chan LW, Easterbrook MG, Li X. Investigation of the influence of mean HPMC particle size and number of polymer particles on the release of aspirin from swellable hydrophilic matrix tablets. J Controlled Release 2001;76:39-49.

30. Draelos ZD, Thaman LA. Cosmetic formulation of skin care product. New York: Taylor and Francis Group; 2006

31. Zebua NF, Putra EDL, Harahap U, Kaban J. Durian seed utilization as a base material of topical gel. Asian J Pharm Clin Res 2018;11:174-7.

32. Garg A, Deepeka A, Garg S, Singla AK. Spreading of semisolid formulation. Pharmaceutical Technology; 2002.

33. Majewicz TG, Ford C. Preparation of CMC with improved substituent uniformity using borax. United States Patent; 1981. 